\title{
Hypothesis: A Role for Fragile X Mental Retardation Protein in Mediating and Relieving MicroRNA-Guided Translational Repression?
}

\author{
Isabelle Plante ${ }^{1,2}$ and Patrick Provost ${ }^{1,2}$ \\ ${ }^{1}$ Centre de Recherche en Rhumatologie et Immunologie, Centre de Recherche du CHUL (CHUQ), 2705 Boulevard, \\ Laurier, Sainte-Foy, Québec, Canada G1V $4 G 2$ \\ ${ }^{2}$ Department of Anatomy and physiology, Faculty of Medicine, Laval University, Québec, Canada G1K 7P4
}

Received 8 April 2006; Accepted 2 May 2006

MicroRNA (miRNA)-guided messenger RNA (mRNA) translational repression is believed to be mediated by effector miRNAcontaining ribonucleoprotein (miRNP) complexes harboring fragile X mental retardation protein (FMRP). Recent studies documented the nucleic acid chaperone properties of FMRP and characterized its role and importance in RNA silencing in mammalian cells. We propose a model in which FMRP could facilitate miRNA assembly on target mRNAs in a process involving recognition of G quartet structures. Functioning within a duplex miRNP, FMRP may also mediate mRNA targeting through a strand exchange mechanism, in which the miRNA* of the duplex is swapped for the mRNA. Furthermore, FMRP may contribute to the relief of miRNA-guided mRNA repression through a reverse strand exchange reaction, possibly initiated by a specific cellular signal, that would liberate the mRNA for translation. Suboptimal utilization of miRNAs may thus account for some of the molecular defects in patients with the fragile $\mathrm{X}$ syndrome.

Copyright (C) 2006 I. Plante and P. Provost. This is an open access article distributed under the Creative Commons Attribution License, which permits unrestricted use, distribution, and reproduction in any medium, provided the original work is properly cited.

\section{THE mIRNA-GUIDED RNA SILENCING MACHINERY AND DISEASES}

MicroRNAs (miRNAs) are small $\sim 21$ - to 24-nucleotide (nt) RNAs that mediate messenger RNA (mRNA) translational repression through recognition of specific partially complementary binding sites usually located in the $3^{\prime}$ nontranslated region (NTR). They are generated by successive processing of stem-loop structured primary miRNAs (pri-miRNAs) and miRNA precursors (pre-miRNAs) by the ribonucleases (RNases) III Drosha [1] and Dicer [2-4], respectively, as reviewed in this issue by Ouellet et al [5]. Encoded by 1-5\% of the genome in eukaryotes, miRNAs may regulate more than $30 \%$ of the genes in humans $[6,7]$ !

Unveiling the complexity of the process, recent studies have identified new protein components involved in miRNAguided RNA silencing, such as DiGeorge syndrome critical region 8 (DGCR8) [8-11], transactivating response (TAR) RNA-binding protein (TRBP) $[12-15]$, and fragile $\mathrm{X}$ mental retardation protein (FMRP) $[16,17]$. Intriguingly, these accessory proteins, which are required for optimal functioning of the pathway, are related to specific human diseases.
Thus, in addition to the emerging causal links between defective miRNAs and human diseases, as reviewed in Ouellet et al [5] and Perron et al [18], some genetic disorders might also be related to malfunctioning of the machinery involved in miRNA biogenesis and function.

DGCR8 was identified in Drosha immunoprecipitates and found to be required for optimal pri-miRNA processing [10]. Both acting within the Microprocessor complex [10], DGCR8 has been proposed to guide Drosha in substrate recognition [11]. Clinically, patients carrying a common monoallelic deletion affecting the DGCR8 gene display phenotypes defined as the DiGeorge syndrome, with manifestations such as congenital heart defects, characteristic facial appearance, immunodeficiency, and behavioral problems $[19,20]$. The possibility that the DiGeorge syndrome is caused by a perturbed Drosha function and/or pri-miRNA processing is attractive, but remains to be established.

As for TRBP, it was identified by proteomic analysis of Dicer immunoprecipitates and reported to assist Dicer function within a pre-miRNA processing complex $[12,13]$. Initially identified in 1991, TRBP was characterized as a cellular factor acting in synergy with the viral Tat protein in the 
transactivation of the long terminal repeat of human immunodeficiency virus type 1 (HIV-1), leading to viral gene transcription [21]. TRBP may thus play a dual role in HIV-1 pathogenesis and RNA silencing, as recently discussed [22].

Two independent groups simultaneously reported a possible relationship between the Drosophila FMRP ortholog (dFMR1) and RNA interference (RNAi). dFMR1 was found to be associated with the effector RNA-induced silencing complex (RISC) as well as miRNAs in Drosophila S2 cells $[16,17]$. In mammalian cells, FMRP was reported to be part of a ribonucleoprotein (RNP) complex with Argonaute 2 (Ago2) and miRNAs [23]. These findings suggest a possible link between the loss of FMRP function in miRNA-guided RNA silencing and the fragile $\mathrm{X}$ syndrome.

\section{FMRP AS A REGULATOR OF TRANSLATION}

In humans, the FMR1 (fragile mental retardation 1) gene, which spans $\sim 38 \mathrm{~kb}$ in the $\mathrm{q} 27.3$ region located at the tip of the $\mathrm{X}$ chromosome long arm, encodes an mRNA of $\sim 3.9 \mathrm{~kb}$ composed of a $\sim 0.2 \mathrm{~kb} 5^{\prime} \mathrm{NTR}$, a $1.9 \mathrm{~kb}$ coding region, and a $1.8 \mathrm{~kb} 3^{\prime}$ NTR [24]. Loss of the FMR1 gene product FMRP is the etiologic factor of the fragile $\mathrm{X}$ syndrome, the most frequent cause of inherited mental retardation $[25,26]$. It affects about 1 in 4000 males, who will develop in almost all cases moderate to severe mental retardation (IQ $\leq 50$ ), and about 1 in 7000 females, who present in general a milder mental handicap [24].

FMRP has been detected in practically every tissue in humans and rodents, with high levels in the brain, testes, esophagus, lung, and kidney [27]. The ability of FMRP to bind RNA, which was first suggested by the presence of Khomology $(\mathrm{KH})$ domains and an RGG box found in various RNA-binding proteins, was later confirmed experimentally $[28,29]$. FMRP is associated with translating polyribosomes in neuronal cells $[30,31]$ and acts, at high levels, as a negative regulator of translation in vitro and in vivo [32-34].

Experimental studies have documented the involvement of FMRP in translational control. When preincubated with mRNAs, FMRP leads to inhibition of translational inhibition both in vitro in the rabbit reticulocyte lysate system and in vivo after microinjection in the Xenopus oocytes [32, 33]. In Drosophila, the dFMR1 protein was reported to downregulate expression of the futsch protein [35]. Expression of high levels of FMRP results in repression of reporter genes in transfected cultured mammalian cells [34]. Although FMRP has been shown to interact with mRNAs and to inhibit translation, its exact role and function are unclear.

More recently, using the recombinant protein, Gabus et al [36] have shown that FMRP possesses nucleic acid chaperone properties, shedding new light on the principal mechanism by which FMRP could regulate gene expression. They observed that FMRP could either anneal or transfer DNA strands of TAR that are perfectly complementary in vitro. Examining these activities in a hammerhead ribozyme model system, the authors noted that FMRP enhanced ribozyme cleavage of an RNA substrate. The KH motifs and RGG box were found to be important for optimal chaperone activity

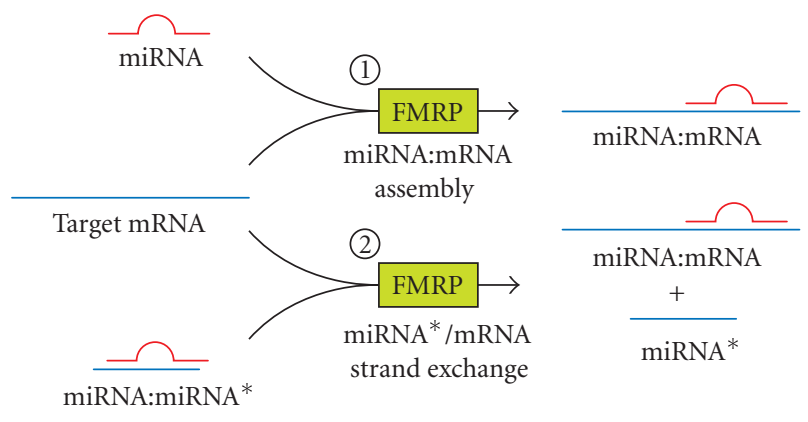

FIGURE 1: FMRP can assemble and exchange strands of RNAs involved in miRNA-guided RNA silencing. Recombinant FMRP can (1) assemble an miRNA to its specific mRNA target, or (2) use an miRNA:miRNA* duplex for mRNA targeting through an RNA strand exchange reaction, which releases the miRNA*.

[36]. These findings suggest that FMRP may regulate translation by acting on the structural status of mRNAs.

Are these nucleic acid chaperone properties of FMRP compatible with, and relevant to, a specific cellular context or regulatory process, such as miRNA-guided RNA silencing?

\section{A ROLE FOR FMRP IN mIRNA-GUIDED RNA SILENCING?}

In Drosophila S2 cells, mRNA-cleaving RNP complexes have been found to contain dFMR1 [16, 17] as well as a single siRNA strand $[37,38]$. Independent groups have shown that target cleavage directed by single-stranded (ss) siRNAs is supported in extracts of HeLa cells [39, 40], from which a human RISC containing ss siRNAs was characterized [40]. In mammalian cells, FMRP was reported to be part of an miRNA-containing RNP (miRNP) complex containing Ago2 [23]. Thus, although the mammalian and fly RNA-silencing machineries differ substantially, they may share two features in common: an RNP complex containing an ssRNA species and a member of the fragile $\mathrm{X}$ family of proteins.

How miRNAs and ss siRNAs are used by the effector RNP complexes for recognition and targeting of regulatable $\mathrm{mR}$ NAs remains poorly understood. However, rather than being the result of a passive hybridization reaction, formation of an miRNA:mRNA or ss siRNA:mRNA transition complex is more likely to be facilitated by a component of the miRNP or siRNP complexes. Capable of promoting RNA folding and hybridization, FMRP represents the most interesting and valuable protein candidate.

\section{FMRP FACILITATES MIRNA ASSEMBLY ON TARGET MRNA}

We verified this possibility and showed that human FMRP can act as an miRNA acceptor protein for Dicer and facilitate assembly of miRNAs on specific target RNA sequences (see Figures 1 and 2) [41]. In these assays, FMRP exhibited a preference for assembling imperfectly paired miRNA:mRNA duplexes, which is the most prevalent situation encountered in mammals. The miRNA assembler property of FMRP was 


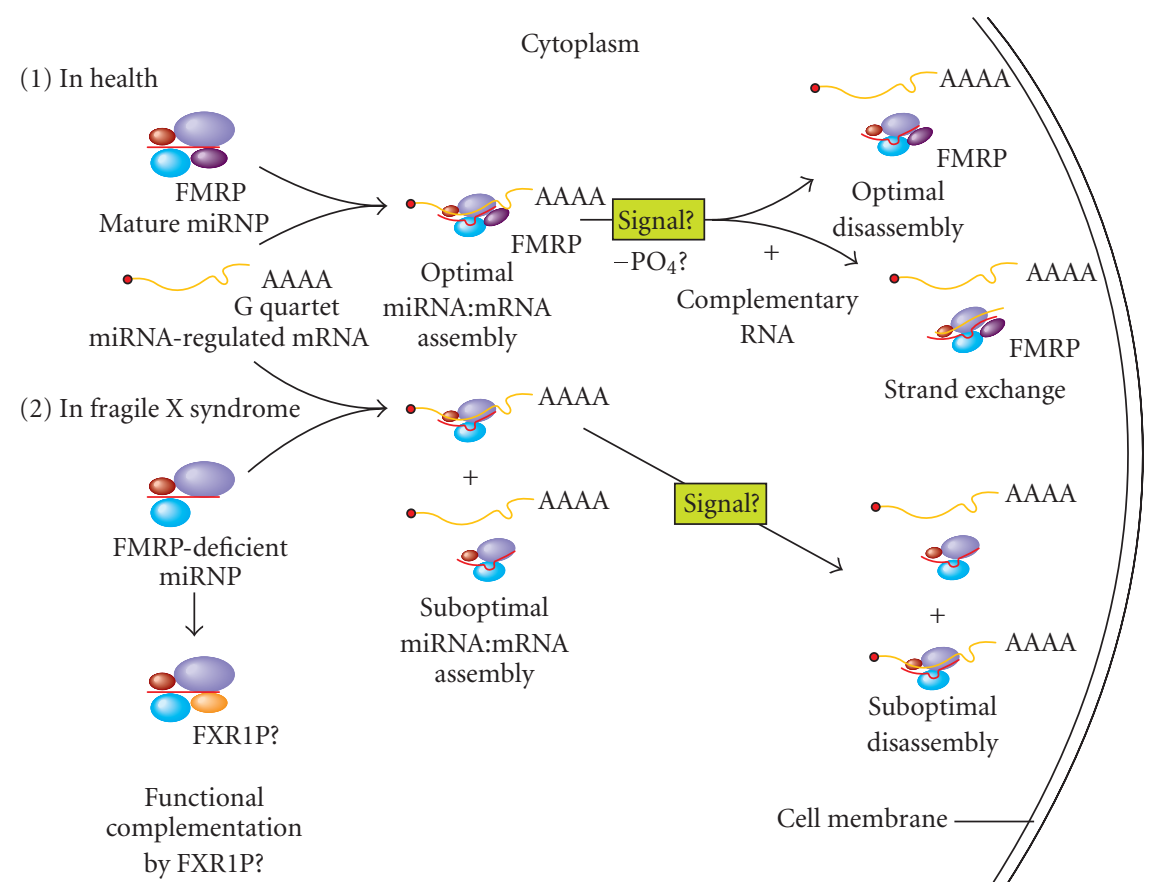

FIGURE 2: Proposed roles and functional regulation of FMRP in miRNA-guided RNA silencing. (1) mRNA targeting by mature miRNPs may involve the concerted assembly of the miRNAs to their binding sites with the recognition of G quartet structures in specific mRNAs by FMRP (in purple). Acting within miRNPs, FMRP may play a key role by relieving translational repression through disassembly of the miRNA:mRNA complexes. mRNAs repressed by miRNPs could thus be reutilized and translated into proteins. This process may be triggered by a cellular signal, possibly a dephosphorylation event. A variant of that phenomenon would have a complementary RNA, like the miRNA*, involved in a strand exchange reaction making the mRNA available for translation, while recycling the miRNP into a duplex miRNAcontaining RNP. (2) In the absence of FMRP, miRNA assembly on target mRNAs may be suboptimal. Moreover, FMRP-deficient miRNPs may be less responsive to signal-induced miRNA:mRNA disassembly, resulting in a suboptimal dissociation from the target mRNAs. In certain tissues where it is expressed, the FXR1P paralog (in orange) may functionally complement, and possibly compensate for, the absence or loss of FMRP expression.

abrogated upon deletion of its RNA-binding $\mathrm{KH}$ domains [41]. In line with these findings, reporter gene silencing assays supported the involvement of FMRP in an ss siRNAcontaining RNP (siRNP) effector complex and revealed its requirement for optimal RNAi in cultured mammalian cells [41]. These data suggest that FMRP may function as the miRNA assembler in RNA silencing.

\section{FMRP CAN EXCHANGE miRNA*/mRNA STRANDS}

Recently, native gel electrophoresis unveiled different RNP complexes containing siRNA duplexes in Drosophila [37, 38], leading the authors to propose a siRNP assembly scheme compatible with conversion of double-stranded (ds) siRNP into ss siRNP. mRNA cleavage activity could only be correlated with the latter complex [37]. siRNA-induced mRNA cleavage and miRNA-guided translational repression may be mediated by different RNP complexes and differ mechanistically. If ss siRNPs induce mRNA cleavage, what about the complexes that mediate inhibition of translation? Do they contain ssRNA or dsRNA, such as miRNA duplexes? In fact, duplex RNA-containing RNPs may be more than precursors of ssRNA-containing RNPs. They may be functionally important in RNA silencing. Whether they are involved in
miRNA-guided translational repression has not been addressed so far.

However, this would require resolution of the "threestrand" enigma, posed by targeting of an ssRNA by dsRNA species. In that context, formation of a specific miRNA:mRNA transition complex from a miRNA:miRNA* duplex and its target RNA would appear as obligatory. Interestingly, human FMRP can do just that! We observed that FMRP can accept and utilize miRNA:miRNA* duplexes, generated upon Dicer processing of pre-miRNAs, to favor miRNA:mRNA complex formation through an miRNA*/mRNA strand exchange reaction [41], as illustrated in Figure 1. Together, these observations suggest that FMRP could facilitate mRNA targeting by acting (i) as an miRNA assembler in ssRNA-containing RNPs, and (ii) as an miRNA*/mRNA strand exchanger in duplex RNAcontaining RNP effector complexes.

\section{IS FMRP INVOLVED IN RELIEVING mRNA REPRESSION?}

Reversibility is a fundamental difference between siRNPmediated mRNA cleavage or miRNP-guided translational repression. If mRNA structural and functional integrity is preserved, silenced mRNAs could be translated again, 
whereas degraded mRNAs could not. In Drosophila, the RISC mediates cleavage of the mRNA target, and is presumably regenerated, allowing for repeated cycles of mRNA inactivation and amplification of the phenomenon [43]. In contrast to the most prevalent situation in flies and plants, mammalian mRNAs are mainly and primarily subjected to miRNP-induced translation repression prior to their relocation to specific cytoplasmic foci, referred to as processing ( $\mathrm{P}$ bodies) [44, 45] or GW182-containing bodies (GW-bodies) [46], where mRNA degradation occurs. This sequence of events is supported by a recent study revealing that mRNAs containing partial miRNA complementary sites are eventually targeted for degradation in vivo, as exemplified by the lin-41 mRNA:let-7 miRNA tandem [47].

Do P-bodies represent the unique and ultimate destination of miRNA-repressed cellular mRNAs? Can these mRNAs be prevented from reaching their final destination? Is there a defined structural or functional point of no return, ahead of which mRNAs could be redirected towards the translation machinery? Most interestingly, can mRNAs escape and return "safe" from P-bodies and be used again for protein synthesis? In these cases, the involvement of a protein having the ability to shuttle between cellular compartments may be expected.

miRNPs may be perceived as translational "locks" and contribute to preserve mRNA structural and functional integrity until it needs to be translated again. Relief of the miRNA-guided translational repression may thus represent a posttranscriptional control of gene expression relevant to situations where specific proteins need to be expressed within minutes under specific circumstances, such as conditions of cellular stress. The exact mechanism and duration of miRNA-induced repression of a given mRNA remain unclear at this point. As well, no information is currently available as to how long the mRNA can be stored when complexed with miRNPs. However, if miRNA repression of mRNAs can be relieved, it would likely involve a coordinated and regulated disassembly of miRNA:mRNA complexes, a process probably executed by a component of miRNPs, such as FMRP.

\section{FMRP MAY ACT AS A MOLECULAR SWITCH IN MIRNA-GUIDED RNA SILENCING}

How could miRNA repression be relieved? It may be initiated upon destabilization of miRNP binding to the repressed mRNA, induced by unknown cellular signals or factors, leading to dissociation of the miRNA:mRNA complex (see Figure 2). Whether differences in strand complementarity of the complexes can contribute or suffice to drive this reaction backward requires further investigation.

Alternatively, the RNA strand exchange properties of FMRP may participate to the relieving of miRNA repression, in a reaction possibly involving the miRNA*, whose fate and function remain obscur. A recent study by Matranga et al [48] showed that the siRNA passenger strand of the duplex is cleaved by Ago 2 in Drosophila embryo lysates. However, the authors showed that passenger-strand cleavage is not important for the incorporation of miRNAs that derive from mismatched duplexes [48]. These observations raise the following question: do miRNAs* play a significant role in RNA silencing?

The possibility that the miRNA* could be used by FMRP like a spare RNA for the mRNA to be relieved from the miRNA repression, as illustrated in Figure 2, is plausible and attractive. Characterized as a chaperone [36], FMRP could bind to one or more nucleic acid molecules and promote the formation of the most stable structure, upon which its continued binding is no longer required to maintain it $[36,49,50]$. The results of our previous study [41] suggest that the miRNA:mRNA complex is more stable than the miRNA:miRNA* duplex. We hypothesize that unknown cellular signals or factors may assist FMRP in executing a reverse strand exchange by lowering the required thermodynamic threshold. The miRNA* may further facilitate that process by providing an appropriate sequence-specific RNA template. The reaction would liberate the mRNA for translation and lead to reconstitution of a duplex miRNP, theoretically available for subsequent rounds of mRNA regulation events.

\section{A ROLE FOR FMRP DEPHOSPHORYLATION IN RNA SILENCING?}

FMRP may function as a molecular device regulating mRNA translation by allowing optimal miRNA assembly or disassembly in response to specific cellular signals or factors. Posttranslational modifications, such as phosphorylation/dephosphorylation events, may regulate FMRP function in RNA silencing, allowing it, for example, to switch between the forward (on) and reverse (off) modes of RNA strand exchange. Drosophila FMR1 is phosphorylated by casein kinase II at serine 406 (Ser406), which is highly conserved among fragile $\mathrm{X}$ family members from several species [51]. This residue is located in close proximity to the RGG box and corresponds to Ser499 [52] or Ser500 [51] (depending on amino acid numbering) in human FMRP, which was also found to be phosphorylated in vivo. Phosphorylation upregulated dFMR1 oligomerization, thereby enhancing the RNA-binding properties of the protein [51]. In contrast to the Drosophila ortholog, the phosphorylation status of mammalian FMRP did not influence its association with specific mRNAs in vivo [52]. The authors, however, found that unphosphorylated FMRP is associated with actively translating polyribosomes, while a fraction of phosphorylated FMRP is associated with apparently stalled polyribosomes [52]. These data suggest that the release of FMRP-induced translational suppression may involve a dephosphorylation signal [52].

\section{FMRP MAY BE A KEY DETERMINANT OF miRNA:mRNA SPECIFICITY}

The presence and importance of FMRP in effector miRNP complexes may explain why FMRP is found associated with several hundreds of different mRNAs [53]. It will be interesting to see what proportion of these mRNAs bound by FMRP $[53,54]$ is experimentally validated and physiologically 


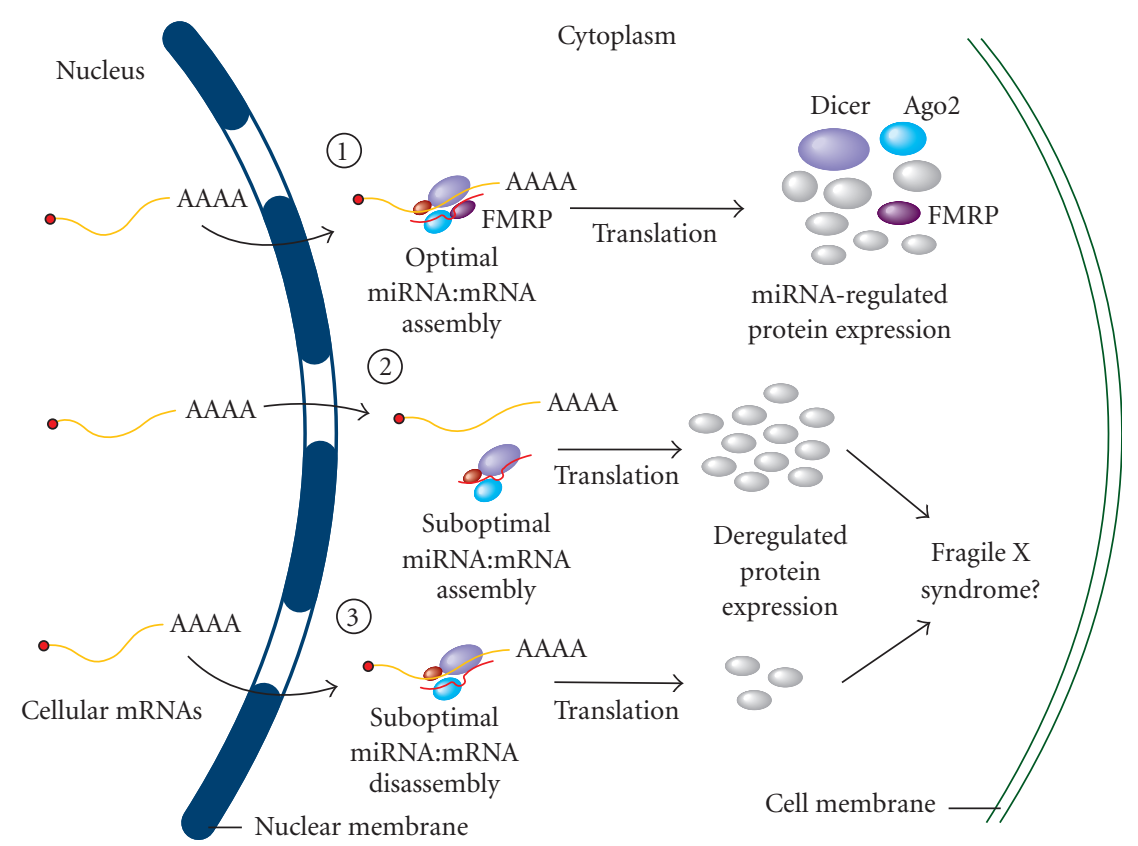

FIGURE 3: A potential role for suboptimal miRNA:mRNA assembly and/or disassembly in the etiology of the fragile X syndrome. (1) miRNA assembly on target mRNAs may be optimal when facilitated by FMRP, which may also be required for optimal relief of miRNA-guided translational repression. (2) In the absence of FMRP, suboptimal miRNA assembly on target mRNAs may lead to overexpression of specific proteins. (3) Whereas suboptimal disassembly of FMRP-deficient miRNPs from target mRNAs may result in a prolonged inhibition of translation. The resulting misbalanced expression of miRNA-regulated genes may alter downstream cellular processes and metabolic pathways (not depicted in this figure) and lead to the development of the fragile $\mathrm{X}$ syndrome.

relevant miRNA targets. Using a bioinformatic approach, John et al [42] observed a strong enrichment of predicted targets in mRNAs associated with FMRP in mammals. FMRP may thus be a key determinant of miRNA:mRNA specificity. This is consistent with the hypothesis that miRNAs act as sequence-specific adaptors in the interaction of RNPs with translationally regulated mRNAs [42]. This interaction may be dictated, on the one hand, by the nucleotide sequence of the miRNA and, on the other hand, by the presence of $G$ quartet structures [55] and/or kissing complex motifs [56] in the mRNA. Therefore, it may not be a coincidence that the FMR1 gene is highly conserved among vertebrates [27], where mRNAs are primarily subjected to miRNP-induced translation repression.

\section{A MOLECULAR BASIS OF THE FRAGILE X SYNDROME?}

The biochemical properties of FMRP make it a prime candidate for a role in mediating and relieving miRNA-guided translational repression. We hypothesize that the absence of FMRP expression may result in suboptimal miRNA assembly on, and/or disassembly from, their natural mRNA targets, leading to a perturbed protein expression profile (see Figure 3). This may be expected given the requirement of FMRP for efficient small RNA-guided gene regulation [41].

The FMRP paralog fragile X-related protein 1 (FXR1P) exhibited miRNA annealing and strand exchange properties similar to FMRP [41]. These data suggest a conserved function for fragile X proteins in RNA silencing and open the possibility that FXR1P may partly complement or compensate for the absence or loss of FMRP expression (see Figure 2).

The next challenge will be to ascertain the ability of FMRP to assemble and exchange miRNA strands in a cellular context. In fact, several additional issues need to be addressed in order to validate the proposed hypothesis. For instance, are these properties of FMRP preserved within miRNPs in vivo? What are the cellular proteins and/or cofactors assisting FMRP function in vivo? Is FMRP able to relieve miRNAguided mRNA repression? If so, what is the mechanistic of that process, that is, the sequence of events, nature of the components involved and/or signal(s) required? When and where in the cell do these events take place? Elucidation of the exact role and function of FMRP in miRNA-guided gene regulation may hold key to determining the molecular basis of the fragile $\mathrm{X}$ syndrome and establishing a causal link between dysfunction of the RNA-silencing machinery and a human genetic disease.

\section{ACKNOWLEDGMENTS}

We are grateful to Edward Khandjian for encouragement and support, Gilles Chabot for graphic design, and members of the Provost laboratory for stimulating discussions. P. Provost is a New Investigator of the Canadian Institutes of Health Research (CIHR). This work was supported by Grant NDG-70190 from CIHR-Institute of Genetics and/or CIHRInstitute of Neuroscience, Mental Health, and Addiction and Grant EOP-64706 from Health Canada/CIHR. P. Provost is the author for correspondence. 


\section{REFERENCES}

[1] Lee Y, Ahn C, Han J, et al. The nuclear RNase III Drosha initiates microRNA processing. Nature. 2003;425(6956):415-419.

[2] Bernstein E, Caudy AA, Hammond SM, Hannon GJ. Role for a bidentate ribonuclease in the initiation step of RNA interference. Nature. 2001;409(6818):363-366.

[3] Provost P, Dishart D, Doucet J, Frendewey D, Samuelsson B, Rådmark $\mathrm{O}$. Ribonuclease activity and RNA binding of recombinant human Dicer. EMBO Journal. 2002;21(21):5864-5874.

[4] Zhang H, Kolb FA, Jaskiewicz L, Westhof E, Filipowicz W. Single processing center models for human Dicer and bacterial RNase III. Cell. 2004;118(1):57-68.

[5] Ouellet DL, Perron MP, Gobeil L-A, Plante P, Provost P. MicroRNAs in gene regulation: when the smallest governs it all. Journal of Biomedicine and Biotechnology. 2006;2006: Article ID 69616, 20 pages.

[6] Lewis BP, Burge CB, Bartel DP. Conserved seed pairing, often flanked by adenosines, indicates that thousands of human genes are microRNA targets. Cell. 2005;120(1):15-20.

[7] Xie X, Lu J, Kulbokas EJ, et al. Systematic discovery of regulatory motifs in human promoters and $3^{\prime}$ UTRs by comparison of several mammals. Nature. 2005;434(7031):338-345.

[8] Denli AM, Tops BBJ, Plasterk RHA, Ketting RF, Hannon GJ. Processing of primary microRNAs by the Microprocessor complex. Nature. 2004;432(7014):231-235.

[9] Landthaler M, Yalcin A, Tuschl T. The human DiGeorge syndrome critical region gene 8 and its D. melanogaster homo$\log$ are required for miRNA biogenesis. Current Biology. 2004; 14(23):2162-2167.

[10] Gregory RI, Yan K-P, Amuthan G, et al. The Microprocessor complex mediates the genesis of microRNAs. Nature. 2004; 432(7014):235-240.

[11] Han J, Lee Y, Yeom K-H, Kim Y-K, Jin H, Kim VN. The Drosha-DGCR8 complex in primary microRNA processing. Genes and Development. 2004;18(24):3016-3027.

[12] Chendrimada TP, Gregory RI, Kumaraswamy E, et al. TRBP recruits the Dicer complex to Ago 2 for microRNA processing and gene silencing. Nature. 2005;436(7051):740-744.

[13] Haase AD, Jaskiewicz L, Zhang H, et al. TRBP, a regulator of cellular PKR and HIV-1 virus expression, interacts with Dicer and functions in RNA silencing. EMBO Reports. 2005; 6(10): 961-967.

[14] Förstemann K, Tomari Y, Du T, et al. Normal microRNA maturation and germ-line stem cell maintenance requires Loquacious, a double-stranded RNA-binding domain protein. PLoS Biology. 2005;3(7):e236.

[15] Saito K, Ishizuka A, Siomi H, Siomi MC. Processing of premicroRNAs by the Dicer-1-Loquacious complex in Drosophila cells. PLoS Biology. 2005;3(7):e235.

[16] Caudy AA, Myers M, Hannon GJ, Hammond SM. Fragile Xrelated protein and VIG associate with the RNA interference machinery. Genes and Development. 2002;16(19):2491-2496.

[17] Ishizuka A, Siomi MC, Siomi H. A Drosophila fragile X protein interacts with components of RNAi and ribosomal proteins. Genes and Development. 2002;16(19):2497-2508.

[18] Perron MP, Boissonneault V, Gobeil L-A, Ouellet DL, Provost P. Regulatory RNAs: future perspectives in diagnosis and personalized therapy. Methods in Molecular Biology. 2006;360: 311-326.

[19] Yamagishi H, Srivastava D. Unraveling the genetic and developmental mysteries of 22q11 deletion syndrome. Trends in Molecular Medicine. 2003;9(9):383-389.
[20] Shiohama A, Sasaki T, Noda S, Minoshima S, Shimizu N. Molecular cloning and expression analysis of a novel gene DGCR8 located in the DiGeorge syndrome chromosomal region. Biochemical and Biophysical Research Communications. 2003;304(1):184-190.

[21] Gatignol A, Buckler-White A, Berkhout B, Jeang K-T. Characterization of a human TAR RNA-binding protein that activates the HIV-1 LTR. Science. 1991;251(5001):1597-1600.

[22] Gatignol A, Laine S, Clerzius G. Dual role of TRBP in HIV replication and RNA interference: viral diversion of a cellular pathway or evasion from antiviral immunity? Retrovirology. 2005;2:65.

[23] Jin P, Zarnescu DC, Ceman S, et al. Biochemical and genetic interaction between the fragile $\mathrm{X}$ mental retardation protein and the microRNA pathway. Nature Neuroscience. 2004;7(2): 113-117.

[24] Bardoni B, Schenck A, Mandel JL. The fragile X mental retardation protein. Brain Research Bulletin. 2001;56(3-4):375-382.

[25] O'Donnell WT, Warren ST. A decade of molecular studies of fragile X syndrome. Annual Review of Neuroscience. 2002;25: 315-338.

[26] Bardoni B, Mandel J-L. Advances in understanding of fragile $\mathrm{X}$ pathogenesis and FMRP function, and in identification of $\mathrm{X}$ linked mental retardation genes. Current Opinion in Genetics and Development. 2002;12(3):284-293.

[27] Khandjian EW. Biology of the fragile X mental retardation protein, an RNA-binding protein. Biochemistry and Cell Biology. 1999;77(4):331-342.

[28] Siomi H, Siomi MC, Nussbaum RL, Dreyfuss G. The protein product of the fragile $\mathrm{X}$ gene, FMR1, has characteristics of an RNA-binding protein. Cell. 1993;74(2):291-298.

[29] Slomi H, Choi M, Siomi MC, Nussbaum RL, Dreyfuss G. Essential role for $\mathrm{KH}$ domains in RNA binding: impaired RNA binding by a mutation in the $\mathrm{KH}$ domain of FMR1 that causes fragile X syndrome. Cell. 1994;77(1):33-39.

[30] Khandjian EW, Corbin F, Woerly S, Rousseau F. The fragile X mental retardation protein is associated with ribosomes. $\mathrm{Na}$ ture Genetics. 1996;12(1):91-93.

[31] Stefani G, Fraser CE, Darnell JC, Darnell RB. Fragile X mental retardation protein is associated with translating polyribosomes in neuronal cells. Journal of Neuroscience. 2004;24(33): 7272-7276.

[32] Laggerbauer B, Ostareck D, Keidel E-M, Ostareck-Lederer A, Fischer U. Evidence that fragile X mental retardation protein is a negative regulator of translation. Human Molecular Genetics. 2001;10(4):329-338.

[33] Li Z, Zhang Y, Ku L, Wilkinson KD, Warren ST, Feng Y. The fragile $X$ mental retardation protein inhibits translation via interacting with mRNA. Nucleic Acids Research. 2001;29(11): 2276-2283.

[34] Mazroui R, Hout ME, Tremblay S, Fillion C, Labelle Y, Khandjian EW. Trapping of messenger RNA by fragile X mental retardation protein into cytoplasmic granules induces translation repression. Human Molecular Genetics. 2002;11(24):30073017.

[35] Zhang YQ, Bailey AM, Matthies HJG, et al. Drosophila fragile $\mathrm{X}$-related gene regulates the MAP1B homolog Futsch to control synaptic structure and function. Cell. 2001;107(5):591603.

[36] Gabus C, Mazroui R, Tremblay S, Khandjian EW, Darlix J-L. The fragile X mental retardation protein has nucleic acid chaperone properties. Nucleic Acids Research. 2004;32(7):21292137. 
[37] Pham JW, Pellino JL, Lee Y, Carthew RW, Sontheimer EJ. A Dicer-2-dependent 80 S complex cleaves targeted mRNAs during RNAi in Drosophila. Cell. 2004;117(1):83-94.

[38] Tomari Y, Du T, Haley B, et al. RISC assembly defects in the Drosophila RNAi mutant armitage. Cell. 2004;116(6):831841.

[39] Schwarz DS, Hutvágner G, Haley B, Zamore PD. Evidence that siRNAs function as guides, not primers, in the Drosophila and human RNAi pathways. Molecular Cell. 2002;10(3):537-548.

[40] Martinez J, Patkaniowska A, Urlaub H, Lührmann R, Tuschl T. Single-stranded antisense siRNAs guide target RNA cleavage in RNAi. Cell. 2002;110(5):563-574.

[41] Plante I, Davidovic L, Ouellet DL, et al. Dicer-derived microRNAs are utilized by the fragile X mental retardation protein for assembly on target RNAs. Journal of Biomedicine and Biotechnology. In press.

[42] John B, Enright AJ, Aravin A, Tuschl T, Sander C, Marks DS. Human microRNA targets. PLoS Biology. 2004;2(11):e363.

[43] Hutvágner G, Zamore PD. A microRNA in a multiple-turnover RNAi enzyme complex. Science. 2002;297(5589): 20562060.

[44] Liu J, Valencia-Sanchez MA, Hannon GJ, Parker R. MicroRNA-dependent localization of targeted mRNAs to mammalian P-bodies. Nature Cell Biology. 2005;7(7):719-723.

[45] Teixeira D, Sheth U, Valencia-Sanchez MA, Brengues M, Parker R. Processing bodies require RNA for assembly and contain nontranslating mRNAs. RNA. 2005;11(4):371-382.

[46] Eystathioy T, Chan EKL, Tenenbaum SA, Keene JD, Griffith K, Fritzler MJ. A phosphorylated cytoplasmic autoantigen, GW182, associates with a unique population of human mRNAs within novel cytoplasmic speckles. Molecular Biology of the Cell. 2002;13(4):1338-1351.

[47] Bagga S, Bracht J, Hunter S, et al. Regulation by let-7 and lin-4 miRNAs results in target mRNA degradation. Cell. 2005; 122(4):553-563.

[48] Matranga C, Tomari Y, Shin C, Bartel DP, Zamore PD. Passenger-strand cleavage facilitates assembly of siRNA into Ago2-containing RNAi enzyme complexes. Cell. 2005;123(4): 607-620.

[49] Herschlag D. RNA chaperones and the RNA folding problem. Journal of Biological Chemistry. 1995;270(36):20871-20874.

[50] Cristofari G, Darlix JL. The ubiquitous nature of RNA chaperone proteins. Progress in Nucleic Acid Research and Molecular Biology. 2002;72:223-268.

[51] Siomi MC, Higashijima K, Ishizuka A, Siomi H. Casein kinase II phosphorylates the fragile $\mathrm{X}$ mental retardation protein and modulates its biological properties. Molecular and Cellular Biology. 2002;22(24):8438-8447.

[52] Ceman S, O’Donnell WT, Reed M, Patton S, Pohl J, Warren ST. Phosphorylation influences the translation state of FMRP-associated polyribosomes. Human Molecular Genetics. 2003;12(24):3295-3305.

[53] Brown V, Jin P, Ceman S, et al. Microarray identification of FMRP-associated brain mRNAs and altered mRNA translational profiles in fragile X syndrome. Cell. 2001;107(4):477_ 487.

[54] Darnell JC, Warren ST, Darnell RB. The fragile X mental retardation protein, FMRP, recognizes G-quartets. Mental Retardation and Developmental Disabilities Research Reviews. 2004;10(1):49-52.

[55] Darnell JC, Jensen KB, Jin P, Brown V, Warren ST, Darnell RB. Fragile X mental retardation protein targets $\mathrm{G}$ quartet mRNAs important for neuronal function. Cell. 2001;107(4):489-499.
[56] Darnell JC, Fraser CE, Mostovetsky O, et al. Kissing complex RNAs mediate interaction between the fragile-X mental retardation protein $\mathrm{KH} 2$ domain and brain polyribosomes. Genes and Development. 2005;19(8):903-918. 

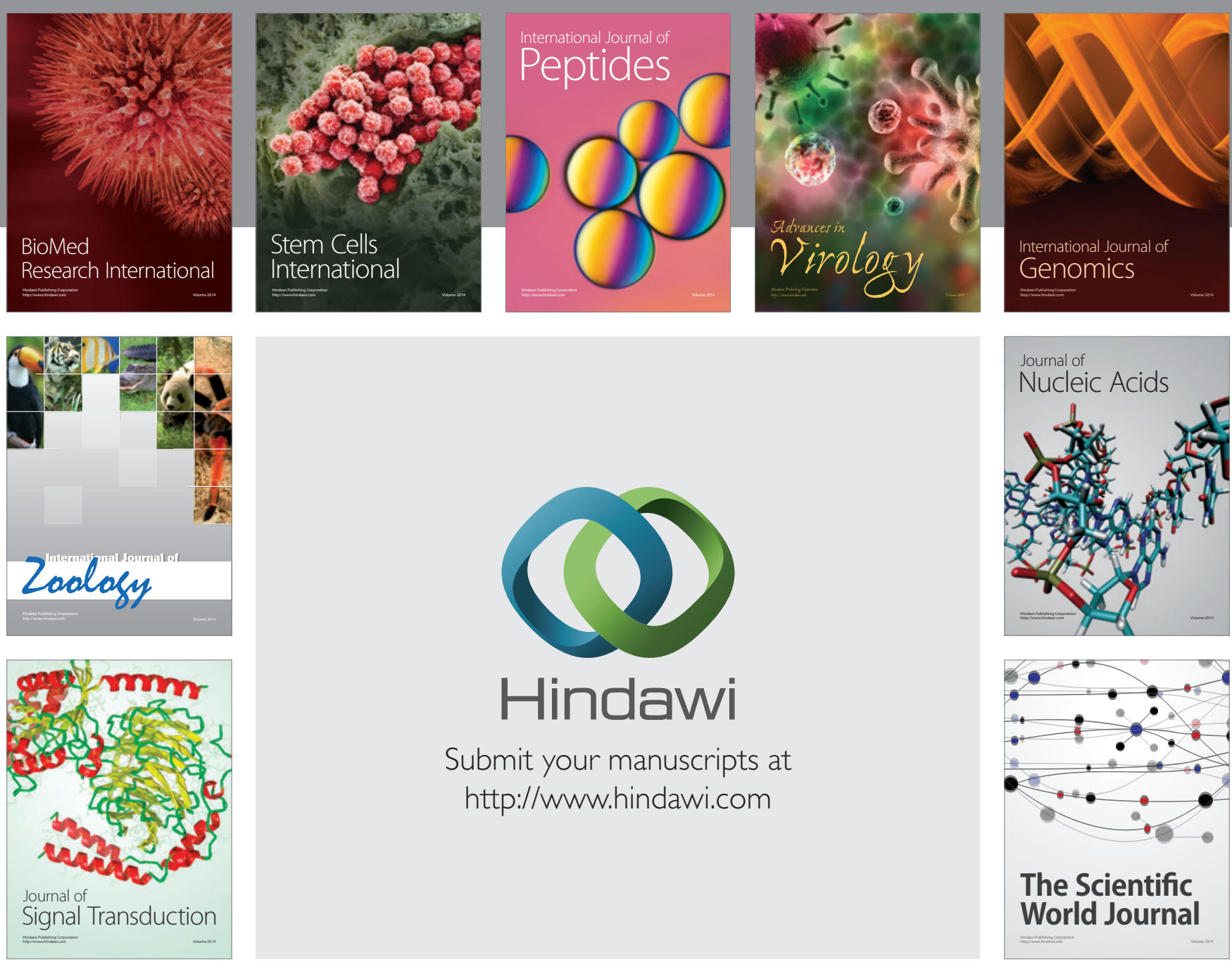

Submit your manuscripts at

http://www.hindawi.com
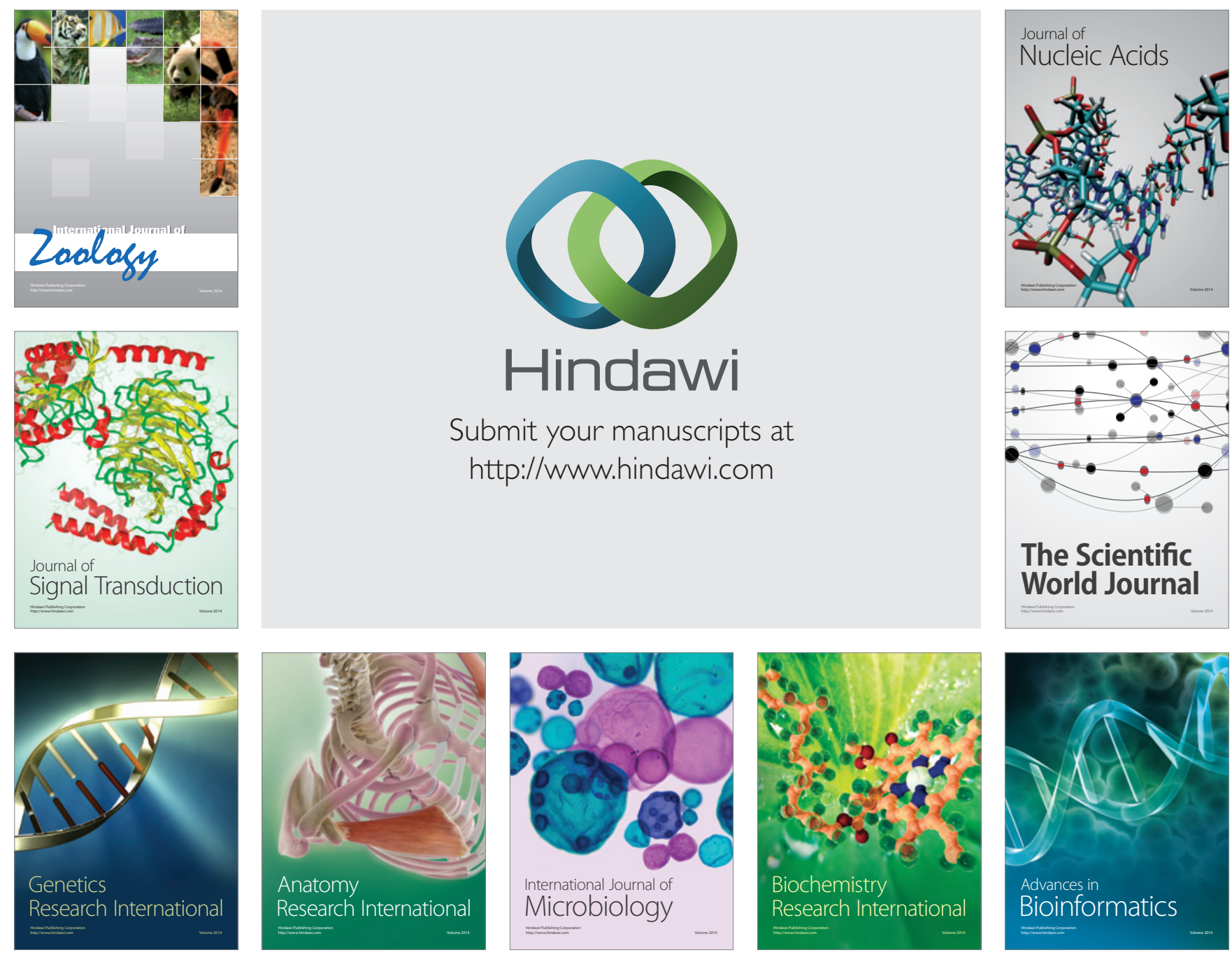

The Scientific World Journal
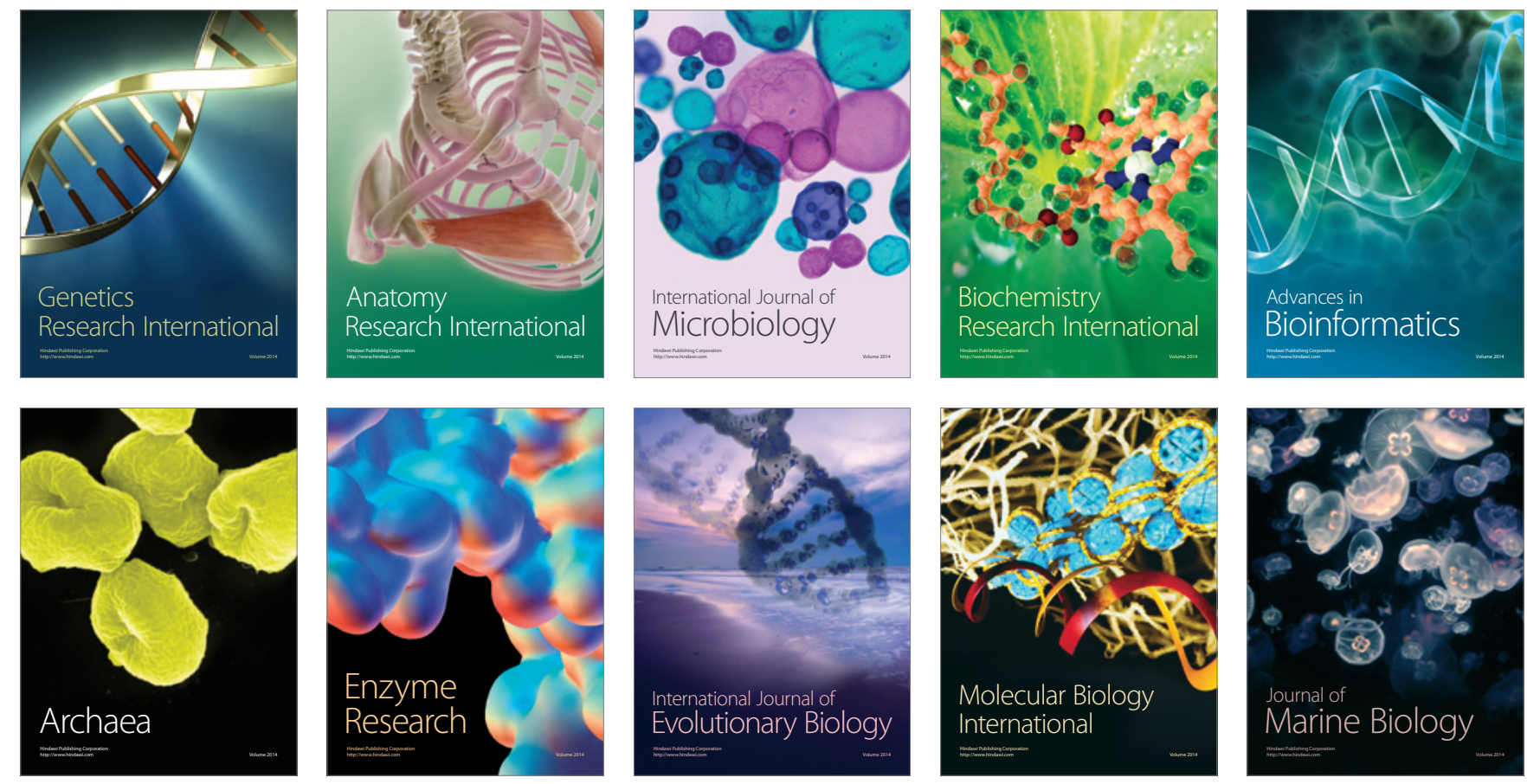